\title{
Pancortin-2 Interacts with WAVE1 and Bcl-xL in a Mitochondria-Associated Protein Complex That Mediates Ischemic Neuronal Death
}

\author{
Aiwu Cheng, ${ }^{1}$ Thiruma V. Arumugam, ${ }^{1}$ Dong Liu, ${ }^{1}$ Rina G. Khatri, ${ }^{1}$ Khadija Mustafa, ${ }^{1}$ Seung Kwak, ${ }^{2}$ Huai-Ping Ling, ${ }^{2}$ \\ Cathleen Gonzales, ${ }^{2}$ Ouyang Xin, ${ }^{1}$ Dong-Gyu Jo, ${ }^{1,3}$ Zhihong Guo, ${ }^{1}$ Robert J. Mark, ${ }^{2}$ and Mark P. Mattson ${ }^{1,4}$ \\ ${ }^{1}$ Laboratory of Neurosciences, National Institute on Aging Intramural Research Program, Baltimore, Maryland 21224, ${ }^{2}$ Neuroscience Discovery Research, \\ Wyeth Research, Princeton, New Jersey $08543,{ }^{3}$ College of Pharmacy, Sungkyunkwan University, Suwon, Korea, and ${ }^{4}$ Department of Neuroscience, Johns \\ Hopkins University School of Medicine, Baltimore, Maryland 21205
}

The actin-modulating protein Wiskott-Aldrich syndrome protein verprolin homologous-1 (WAVE1) and a novel CNS-specific protein, pancortin, are highly enriched in adult cerebral cortex, but their functions are unknown. Here we show that WAVE1 and pancortin-2 interact in a novel cell death cascade in adult, but not embryonic, cerebral cortical neurons. Focal ischemic stroke induces the formation of a protein complex that includes pancortin-2, WAVE1, and the anti-apoptotic protein Bcl-xL. The three-protein complex is associated with mitochondria resulting in increased association of Bax with mitochondria, cytochrome $c$ release, and neuronal apoptosis. In pancortin null mice generated using a Cre-loxP system, ischemia-induced WAVE1-Bcl-xL interaction is diminished, and cortical neurons in these mice are protected against ischemic injury. Thus, pancortin-2 is a mediator of ischemia-induced apoptosis of neurons in the adult cerebral cortex and functions in a novel mitochondrial/actin-associated protein complex that sequesters Bcl-xL.

Key words: pancortin; WAVE1; cerebral ischemia; stroke; neuronal cell death; Bcl-xL

\section{Introduction}

Stroke, a major cause of morbidity and mortality worldwide, typically involves ischemia-induced death of neurons in the cerebral cortex (Truelsen and Bonita, 2003). There are currently no treatments available that can prevent the death of neurons in stroke, and it is therefore critical to establish the molecular mechanisms responsible for neuronal death to identify novel targets for therapeutic intervention. In contrast to the rapid necrosis that occurs in the ischemic core tissue, neuronal apoptosis in the surrounding penumbra occurs over periods of hours to days after the ischemic event, a time window available for therapeutic interventions that target apoptosis. Ischemic apoptosis may be triggered by oxidative stress and overactivation of glutamate receptors leading to mitochondrial membrane permeabilization and release of cytochrome $c$ and activation of caspases (Marzo et al., 1998; Dirnagl et al., 1999; Mattson and Kroemer, 2003). The Bcl-2 family of proteins plays a key role in determining whether neurons resist or succumb to apoptosis, including neurons vulnerable in ischemic brain injury (Mattson and Kroemer, 2003; Polster and Fiskum, 2004). In response to an apoptotic stimulus, proapoptotic family members such as Bax and Bad translocate to

Received 0ct. 4, 2006; revised Jan. 2, 2007; accepted Jan. 2, 2007

This work was supported by the National Institute on Aging Intramural Research Program. We thank Mohammed Mughal for managing the mouse colony and Judith Medoff for help with genotyping.

Correspondence should be addressed to Robert J. Mark, MERCK Research Labs WP26-265, 770 Sumneytown Pike, West Point, PA 19486-0004. E-mail: robert_mark@merck.com.

D01:10.1523/JNEUROSCI.5154-06.2007

Copyright $\odot 2007$ Society for Neuroscience $\quad$ 0270-6474/07/271519-10\$15.00/0 the mitochondrial membrane, where they induce membrane pore formation and cytochrome $c$ release. Anti-apoptotic members such as Bcl-2 and Bcl-xL may prevent apoptosis by blocking the ability of proapoptotic members to induce pore formation (Ghribi et al., 2001; Zong et al., 2001; Basanez et al., 2002)

The actin cytoskeleton and several actin-associated proteins have been implicated in apoptosis. Changes in actin filaments occur during apoptosis, including increased association of actin with mitochondria, which precedes Bax translocation (Tang et al., 2006). Pharmacological and genetic manipulations of actin polymerization have shown that actin depolymerization can protect neurons against apoptotic, excitotoxic, and ischemic death (Furukawa et al., 1997; Trapp et al., 2001; Harms et al., 2004). Wiskott-Aldrich syndrome proteins (WASPs) are a family of actin-regulating proteins that include Wiskott-Aldrich syndrome protein verprolin homologous-1 (WAVE1). WAVE1 contains a C-terminal WASP homology, cofilin-binding, acidic domain (WCA) region, which has been shown to be essential for the regulation of actin cytoskeletal dynamics (Machesky et al., 1999; Banzai et al., 2000; Zalevsky et al., 2001). WAVE1 is kept inactive through its association with four other proteins: Abi (Abelson interacting protein), PIR121, Nap1 (nucleosome assembly protein 1), and HSPC300 (hematopoietic stem progenitor cell 300) (Stradal et al., 2004). When activated by Rac, the WCA region serves as a scaffold to bind monomeric actin via the $\mathrm{WH} 2$ domain and also associates with the actin-related protein 2/3 (Arp2/3) complex at the acidic domain, resulting in actin polymerization. The signaling cascade that transduces extracellular stimuli to the 
actin filaments is governed by small GTPases of the $r$ family (Takenawa and Miki, 2001). In addition to regulating actin polymerization, WAVE1 assembles signaling complexes and targets them to specific compartments, including the plasma membrane, centrosome, and mitochondria (Carnegie and Scott, 2003; Danial et al., 2003). Mitochondrial translocation of cofilin occurs in cells undergoing apoptosis (Chua et al., 2003), and it was recently reported that WAVE1 exists in a mitochondria-associated complex that contains Bad (Danial et al., 2003), suggesting a role for WAVE1 in apoptosis.

Pancortins/olfactomedins were identified by mRNA differential display conducted to search for genes that are brainspecific in rodents (Nagano et al., 1998, 2000). The pancortin gene produces four different forms of proteins (pancortins 1-4) that share a common region in the middle of the protein but differ in their $\mathrm{N}$-terminal (A1 or A2) and C-terminal (C1 or $\mathrm{C} 2$ ) domains. Based on the $\mathrm{N}$-terminal sequence that is conserved within each group, pancortins are classified into two groups (A1- and A2pancortins). A1-pancortins [pancortin-1 and pancortin-2 (Pan-2)] are thought to be intracellular proteins, whereas A2 pancortins (pancortin-3 and -4) are secreted proteins (Nagano et al., 2000; Ando et al., 2005). The function of any of the pancortins is unknown. In the present study, we provide evidence that pancortin-2 plays a pivotal role in the death of adult cortical neurons after an ischemic stroke and that pancortin-2 forms a mitochondriaassociated complex with WAVE1 and $\mathrm{Bcl}-\mathrm{xL}$ that promotes the interaction and apoptotic functions of Bax with mitochondria resulting in cytochrome $c$ release and apoptosis.

\section{Materials and Methods}

Generation and characterization of pancortindeficient mice. To eliminate all four protein isoforms of pancortin, we designed a targeting vector to delete exon M2 (common to all isoforms) and exon Y. The neo-selection cassette was substituted in place of exon $\mathrm{Y}$ in the target construct, whereas exon M2 was flanked by the loxP sequence to provide flexibility should constitutive pancortin deletion result in embryonic lethality. BAC (bacterial artificial chromosome) clones and embryonic stem (ES) cells were derived from the $129 /$ SvEvBrd mouse strain. Construct generation, homologous recombination in ES cells, and generation of chimeric founders were performed by Lexicon Genetics (The Woodlands, TX) Mating of F1 generation mice to Protamine-Cre transgenic mice yielded pancortin knock-out mice that lacked exons M2 and Y and were devoid of all pancortin protein isoforms (see Results). Pancortin knock-out mice were

B
E12 E14 E16 E18 P0 P5 P15 Adult

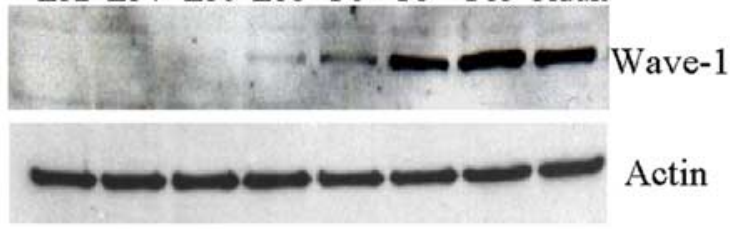

E12 E14 E16 E18 P0 P5 P15 Adult
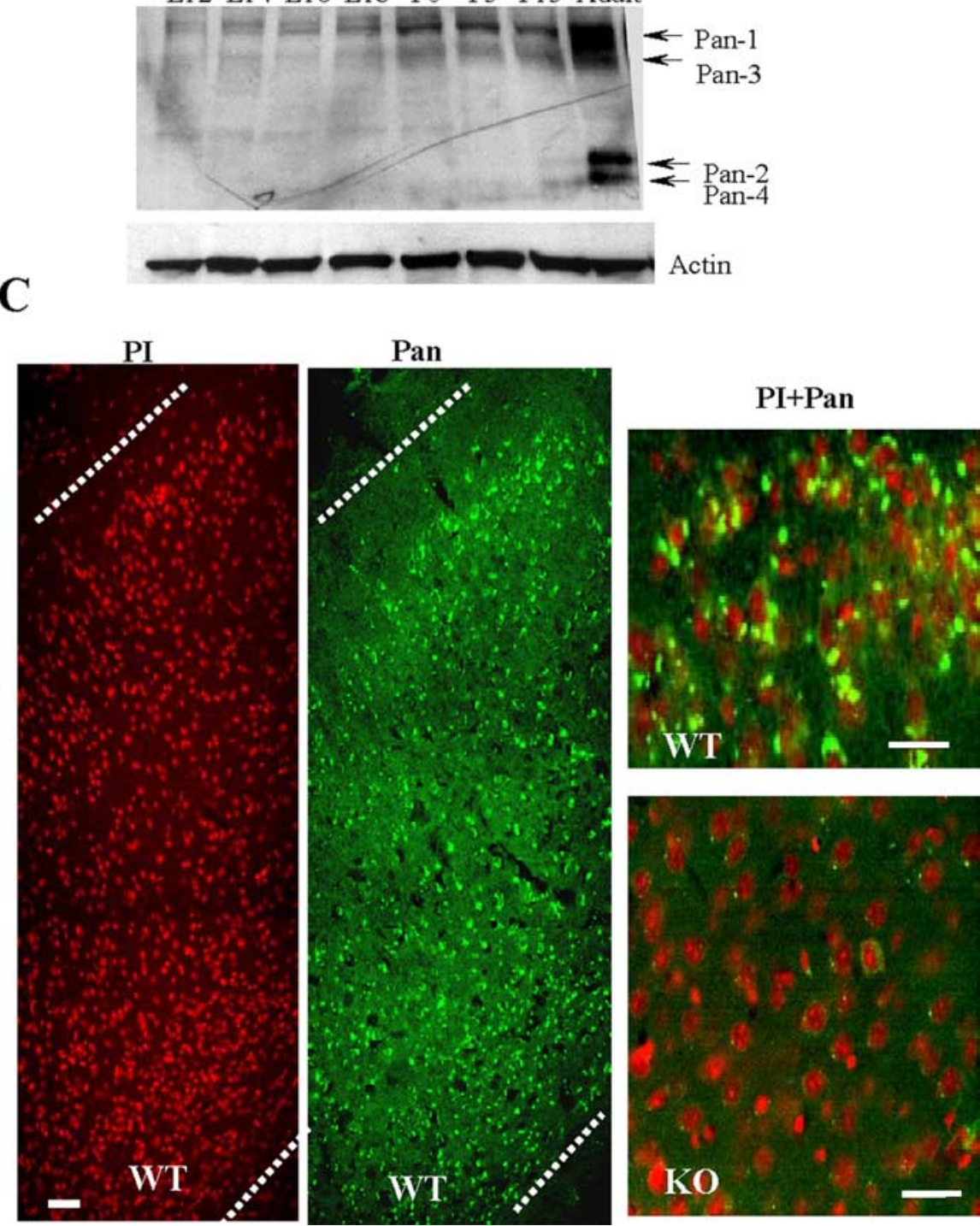

Figure 1. WAVE1 and pancortins are enriched in the adult mouse brain. $\boldsymbol{A}, \boldsymbol{B}$, Immunoblots for WAVE1 and pancortins in samples of embryonic (E12-E18), postnatal (P0-P15), and adult mouse cerebral cortex. C, Immunofluorescence imaging for pancortins (Pan; green) in cerebral cortex of adult WT mice and pancortin ${ }^{-1-}$ mice (KO). A section of cerebral cortex with pancortin staining is shown. The dotted lines label the pial surface and the border between gray matter and white matter. Many cortical neurons in WT mice exhibit pancortin immunoreactivity, whereas no immunoreactivity is present in pancortin-deficient mice. The brain sections were counterstained with propidium iodide (PI; red) to label nuclei. A higher magnification of pancortin staining in cerebral cortex is shown. Scale bar, $20 \mu \mathrm{m}$.

maintained on the 129/SvEvBrd background strain and wild-type (WT) and pancortin $^{-1-}$ littermate male mice were used for experiments. To genotype the mice, two complementary PCRs were performed. The first reaction used primers (5'-CGCTGTCAGCAAGGACACTC-3' and 5-CTCCA 
A

B
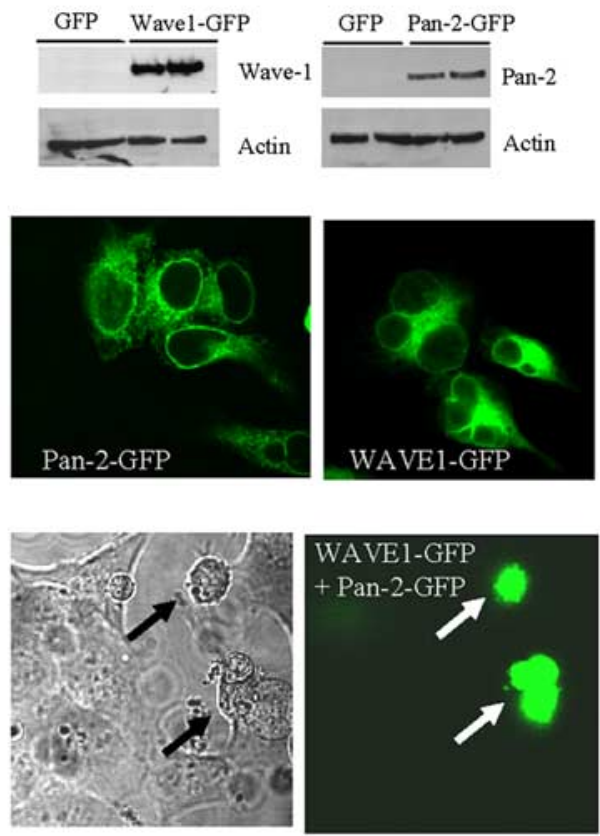

D

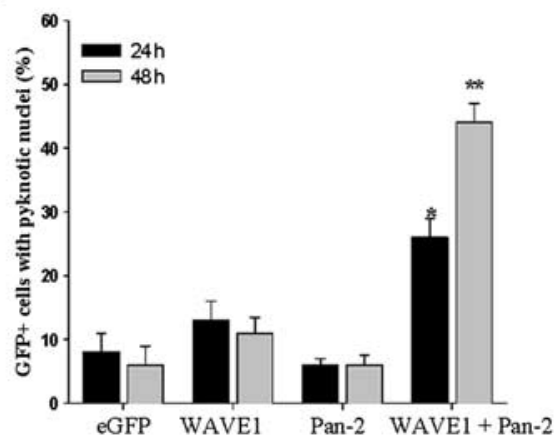

HEK 293 Cells
C
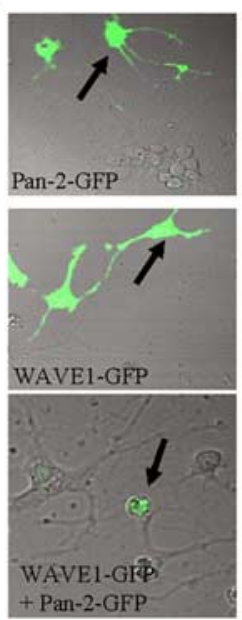

$\mathbf{E}$

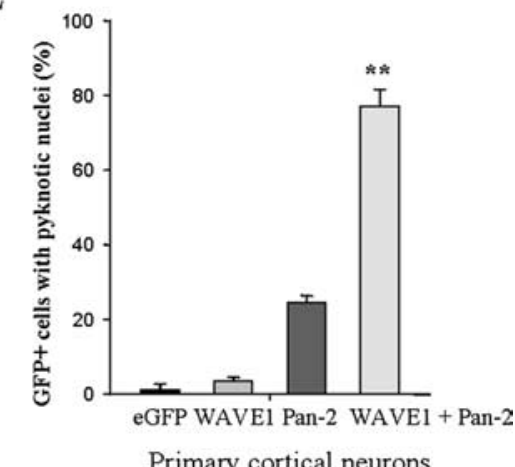

Primary cortical neurons

Figure 2. WAVE1 and pancortin-2 interact functionally to induce apoptosis. $\boldsymbol{A}$, Immunoblot shows the overexpression of WAVE1-GFP and pancortin-2-GFP after 3 d of transfection in HEK293 cells. $\boldsymbol{B}-\boldsymbol{E}$, Coexpression of WAVE1-GFP and pancortin-2GFP in HEK 293 cells $(\boldsymbol{B}, \boldsymbol{D})$ and primary cultured cortical neurons $(\boldsymbol{C}, \boldsymbol{E})$ caused cell death, whereas expression of either WAVE1-GFP or pancortin-2-GFP alone did not. Immunofluorescence images of HEK293 (B) or cortical neuronal (C) GFP ${ }^{+}$cells overexpressing WAVE1 and pancortin-2 alone or in combination were shown. Expression of both WAVE1 and pancortin-2 results in cell shrinkage and the appearance of pyknotic nuclei. $\boldsymbol{D}, \boldsymbol{E}$, Values are the mean and SEM from three independent experiments. ${ }^{*} p<0.05$.

CGTACTGCAGGTC-3' ${ }^{\prime}$ ), which amplify intronic sequences that flank exon $\mathrm{M} 2$, resulting in a $380 \mathrm{bp}$ product corresponding to the wild-type pancortin allele. The second reaction used primers (5'-CGCTGTC AGCAAGGACACTC-3' and 5'-GCACTGACGTCAGATTCTGG-3') flanking the $5^{\prime}$ and $3^{\prime}$ loxP sites, resulting in a 618 bp product corresponding to the pancortin null allele (see Fig. 3C). The genomic DNA from mouse tail biopsies was isolated using a Wizard SV Genomic DNA purification kit (Promega, Madison, WI) according to the manufacturer's protocol. The PCR amplification protocol included 30 cycles at 94,58 , and $72^{\circ} \mathrm{C}$ for $30 \mathrm{~s}$ each with a final extension step at $72^{\circ} \mathrm{C}$ for $7 \mathrm{~min}$. Bands were resolved in a $1 \%$ agarose gel.

Histology and pancortin immunohistochemistry. The mice were anesthetized by inhalation of isoflurane and were perfused transcardially with PBS followed by $4 \%$ paraformaldehyde in PBS, pH 7.4. Brains were postfixed for $48 \mathrm{~h}$ and cryoprotected in 30\% sucrose in PBS for at least $3 \mathrm{~d}$. Then, brains were embedded in OCT and sectioned in the coronal plane at $30 \mu \mathrm{m}$ thickness. Pancortin monoclonal antibody was diluted (1:20) in blocking solution (5\% normal goat serum and $0.4 \%$ Triton X-100 in PBS). After overnight incubation, the free-floating sections were rinsed in PBS and incubated for $2 \mathrm{~h}$ in FITC-conjugated goat anti-mouse IgG
(Jackson ImmunoResearch) diluted in PBS (1: 200). The labeled sections were rinsed and counterstained with propidium iodide $(0.02 \%$ plus $1 \%$ RNase), a red fluorescent dye that labels all nuclei. They were then washed with PBS and mounted on microscope slides in PermaFluor mounting medium (Immunon, Pittsburgh, PA). Fluorescence images were acquired by confocal microscopy (LSM-510; Zeiss, Oberkochen, Germany) using a $10 \times$ or $40 \times$ objective in dual-scanning mode for simultaneous detection of fluorescein ( $488 \mathrm{~nm}$ excitation and $510 \mathrm{~nm}$ emission) and propidium iodide ( $545 \mathrm{~nm}$ excitation and $590 \mathrm{~nm}$ emission). Some images were montaged to show large regions of cerebral cortex.

Focal brain ischemia. Adult male Wistar rats (290-310 g; Charles River Laboratories, Wilmington, MA) were anesthetized with $3 \%$ isoflurane in $70 \%$ nitrous oxide and $30 \%$ oxygen through a nose cone. Temperature was maintained at $37^{\circ} \mathrm{C}$ throughout the surgery using a heating lamp. Transient middle cerebral artery occlusion (MCAO) was induced for 90 min using the intraluminal suture methods. Briefly, an $18 \mathrm{~mm}$ length of 4-0 monofilament nylon suture coated with poly-L-lysine and a flame-rounded tip was inserted into the external carotid artery and advanced through the internal carotid to occlude the origin of the middle cerebral artery. Sham-operated controls were subject to the same surgery but without advancement of the sutures into the MCAO. The contralateral and ipsilateral cortical tissues after MCAO at different time point are collected.

Adult male 3-month-old wild-type and pancortin $^{-1-}$ mice weighing $25-28 \mathrm{~g}$ were used for stroke studies. Permanent focal cerebral ischemia was induced by electrocoagulation of the MCA as described previously (Liu et al., 2002). Mice were anesthetized with isoflurane vapor, and body temperature was maintained at $37^{\circ} \mathrm{C}$ throughout the surgical procedure and recovery periods. Cerebral blood flow was measured by laser-Doppler flowmetry using a flexible 0.5 $\mathrm{mm}$ fiber optic probe (Perimed, Stockholm, Sweden). Mice were killed at $24 \mathrm{~h}$ after MCA occlusion with a lethal dose of isoflurane. The brain tissues were either collected for biochemistry studies or processed for 2,3,5-triphenyltetrazolium chloride (TTC) staining to quantify the infarct volume. For TTC staining, the brains were rinsed in cold PBS and cut into 2-mm-thick coronal sections, incubated for $30 \mathrm{~min}$ in $2 \%$ in PBS, and imaged. The area of infarct, identified by the lack of TTC staining, was measured on the rostral and caudal surfaces of each slice and numerically integrated across the thickness of the slice (OpenLab software; Improvision, Lexington, MA). Volumes from all slices were summed to calculate total infarct volume. Infarct volume was corrected for swelling by comparing the volume of neocortex in the infarcted hemisphere and the noninfarcted hemisphere.

Immunoprecipitation and immunoblot analysis. For immunoprecipitation analysis, brain tissues were solubilized in lysis buffer $(150 \mathrm{~mm} \mathrm{NaCl}$, $20 \mathrm{~mm}$ Tris, pH 7.2, 1.0\% Triton X-100, 1\% deoxycholate, and $5 \mathrm{~mm}$ EDTA) with proteinase inhibitor cocktail (Roche Diagnostics, Indianapolis, IN). Protein concentrations were determined using a BCA assay kit from Bio-Rad (Hercules, CA) with a BSA standard. Equal amounts of protein extracts $(0.5-1.0 \mathrm{mg})$ were precleared by incubating with $50 \mu \mathrm{l}$ of protein A/G agarose (Santa Cruz Biotechnology, Santa Cruz, CA) for $1 \mathrm{~h}$ at $4^{\circ} \mathrm{C}$ on a rotating shaker and were then centrifuged to precipitate the 
beads. Supernatant was collected, incubated with $5 \mu \mathrm{g}$ of antibodies against either WAVE1 (rabbit polyclonal) or pancortins (mouse monoclonal antibody) overnight at $4^{\circ} \mathrm{C}$ in a shaker. The samples were then mixed with $100 \mu \mathrm{l}$ of protein A/G agarose and incubated for $2 \mathrm{~h}$. Pellet protein $A / G$ beads by centrifugation were repeatedly washed four times with $1 \mathrm{ml}$ of lysis buffer, the final pellets were eluted in protein loading buffer, and samples were vortexed and boiled for $3 \mathrm{~min}$. Beads were precipitated by centrifugation, and supernatants were collected for immunoblot analysis. For immunoblot analysis, protein extracts from mouse cerebral cortex were prepared by solubilizing the brain tissue in SDS-PAGE sample buffer. Protein concentrations were determined using a BCA assay kit from Bio-Rad with a BSA standard. Samples were prepared with protein loading buffer for immunoblot analysis. All protein samples were resolved (50-100 $\mu$ g per lane) in a $4-15 \%$ SDSpolyacrylamide gel at $100 \mathrm{~V}$. Proteins were transferred to $0.2 \mu \mathrm{m}$ nitrocellulose membrane, and membranes were blocked with $4 \%$ nonfat milk in Tris-buffered saline-Tween 20 for $2 \mathrm{~h}$. Membranes were incubated overnight in primary antibody in $4 \%$ nonfat milk. Membranes were washed and then incubated for $1 \mathrm{~h}$ in the presence of a 1:5000 dilution of secondary antibody (anti-mouse or anti-rabbit IgG) conjugated to horseradish peroxidase. Reaction products were visualized by using an ECL Western Blot Detection kit (GE Healthcare, Piscataway, NJ). The antibodies used are listed as follows: anti-pancortin (1:20), anti-Bax (1: 500; Santa Cruz Biotechnology), anti-actin (1:5000; Sigma, St. Louis, MO), anti-WAVE1 (1:1000), anti-Bcl-xL (1:1000; Cell Signaling Technology, Beverly, MA), anti-HSP (heat shock protein; 1:1000; Santa Cruz Biotechnology).

Subcellular fractionation. Brains were homogenized with 10 strokes of a Teflon Dounce homogenizer in buffer A (in mm: 250 sucrose, 10 HEPES-KOH, pH 7.5, $10 \mathrm{KCl}, 1$ EGTA, 2 EDTA, 0.15 spermine, and 0.75 spermidine) containing a proteinase inhibitor mixture (Sigma). The homogenates were centrifuged twice at $1000 \times g$ for $10 \mathrm{~min}$ at $4^{\circ} \mathrm{C}$. The supernatants were centrifuged at $10,000 \times g$ for $15 \mathrm{~min}$ at $4^{\circ} \mathrm{C}$. The resulting crude mitochondria pellets were layered onto a 1:1 Percoll/ $2 \times$ buffer A gradient and centrifuged at 50,000 $\times g$ for $1 \mathrm{~h}$. The mitochondrial layer, in the middle of the gradient, was collected and washed in homogenization buffer and then resuspended in buffer $\mathrm{A}$ and frozen in multiple aliquots at $-80^{\circ} \mathrm{C}$. The supernatant of the $10,000 \times g$ spin was further centrifuged at $100,000 \times g$ for $1 \mathrm{~h}$ at $4^{\circ} \mathrm{C}$. The supernatant (cytosolic fraction) was divided into aliquots, and the pellets (microsomal fraction) were frozen at $-80^{\circ} \mathrm{C}$. Before immunoblot analysis, the fractions were prepared by solubilizing in lysis sample buffer. Protein concentrations were determined using a BCA assay kit from Bio-Rad with a BSA standard.

Antibodies. WAVE1 rabbit polyclonal antisera were generated against the peptide GIRPSSPVTVTALAHP, corresponding to amino acids 436451 of the WAVE protein. Rabbits were immunized with a KLHconjugated synthetic peptide, and antisera were isolated by Pocono Rabbit Farm and Laboratory (Canadensis, PA). WAVE1 monoclonal antibody 20.2 was generated against the KLH-conjugated peptide KQKQKNLDRPHEPEVPRAPHD, corresponding to amino acids $178-$ 199 of the WAVE protein. Pancortin monoclonal antibody 7.1 was generated against the peptide MRGLESKFKQVEESHKQHLARQ, corresponding to amino acids $129-150$ of pancortin-2. Hybridoma supernatants were screened for their ability to recognize full-length WAVE or pancortin by immunocytochemistry in transfected COS 7 cells and by immunoblot analysis.

Plasmid construction, transfection, and cell survival analysis. WAVE1 and pancortin green fluorescent protein (GFP) fusion constructs were made using standard molecular biology cloning techniques. WAVE1 and pancortin-2 were cloned into the EcoRI and BamHI sites of the pEGFP vector (Clontech, Mountain View, CA). Human embryonic kidney 293 (HEK293) cells and primary cultured cortical neurons were transfected with GFP empty vector, full-length WAVE-GFP, full-length Pan-2-GFP or WAVE-GFP plus Pan-2-GFP using an Invitrogen (Carlsbad, CA) Lipofectamine 2000 kit. The percentage of cells with fragmented and pyknotic nuclei were scored at 24 and $48 \mathrm{~h}$ after transfection, after fixation and staining with Hoechst 33258 as described previously (Cheng et
$\mathbf{A}$

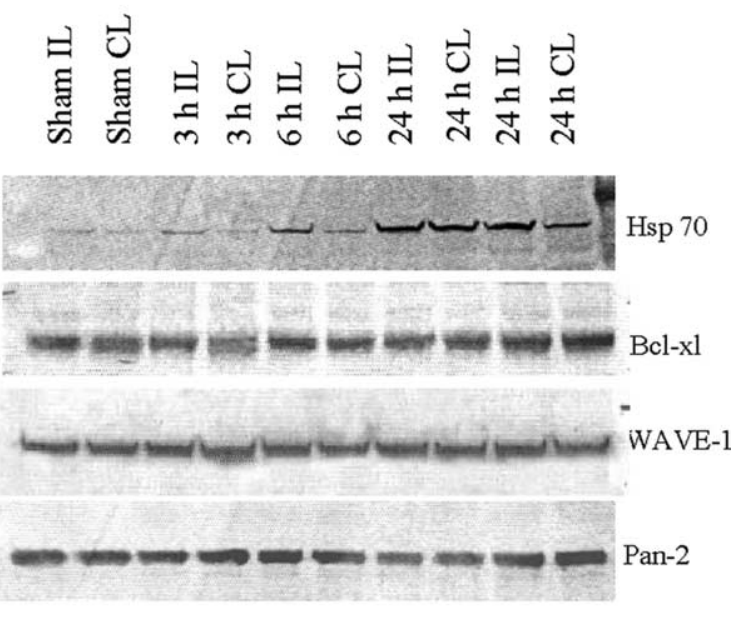

B

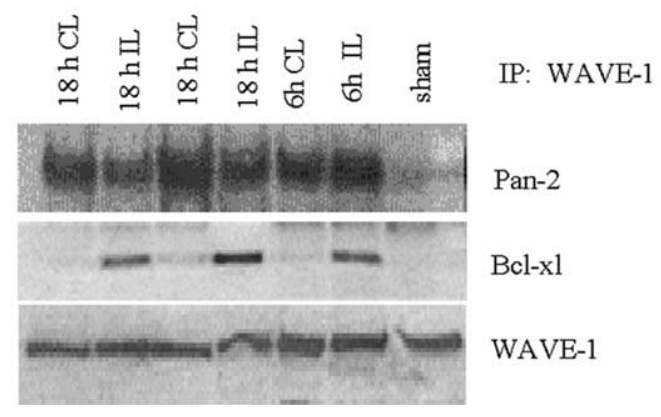

Figure 3. Focal brain ischemia induces the formation of a WAVE1/pancortin/BCl-xL protein complex. A, Immunoblot for WAVE1, pancortin-2, BCl-xL, and Hsp70 in samples of contralateral (CL) and ipsilateral (IL) cortical tissues lysates from sham or MCA0 mice at different time points. $\boldsymbol{B}$, The lysates were immunoprecipitated with WAVE1 antibodies and subjected to immunoblotting with antibodies to pancortin- 2 and BCl-xL. The blots were reprobed with WAVE1 antibodies to control for protein loading. IP, Immunoprecipitation.

al., 2001). Approximately 100 (neurons) or $500 \mathrm{GFP}^{+}$cells $(293$ cells) from each culture were scored manually for apoptotic nuclei.

Primary cortical neuronal culture and cell survival analysis. Pancortin $^{+/-}$female mice were mated with pancortin ${ }^{+/-}$male mice to generate timed-pregnant mice [embryonic day 15 (E15)]. Primary cortical neuronal cultures were established from individual embryonic neocortex by protocol as described previously (Glazner and Mattson, 2000). The body of each embryo was collected for DNA extraction and PCR genotyping. Cells were plated at a density of 50,000 cells $/ \mathrm{cm}^{2}$ on $12 \mathrm{~mm}$ diameter glass coverslips in 24 -well plates. The coverslips were coated with polyethyleneimine (Sigma). The culture medium consisted of Neurobasal medium with B27 supplements (Invitrogen); cultures were maintained in a $95 \%$ room air and $5 \% \mathrm{CO}_{2}$ humidified atmosphere at $37^{\circ} \mathrm{C}$. To induce apoptosis, the cultures at day 5 were switched to Neurobasal medium without B27 supplements for $48 \mathrm{~h}$. Cell death was quantified by staining cells with Hoechst 33258 and determining the percentage of cells with pyknotic nuclei.

\section{Results}

WAVE1 interacts with pancortin-2 and Bcl-xL to form a protein complex in response to focal ischemic stroke

The expression of both pancortin and WAVE1 are restricted to the CNS in postnatal rodents (Nagano et al., 1998; Dahl et al., 2003). Immunoblot analysis of cortical homogenates showed that the level of both pancortins and WAVE1 are very low in 
A

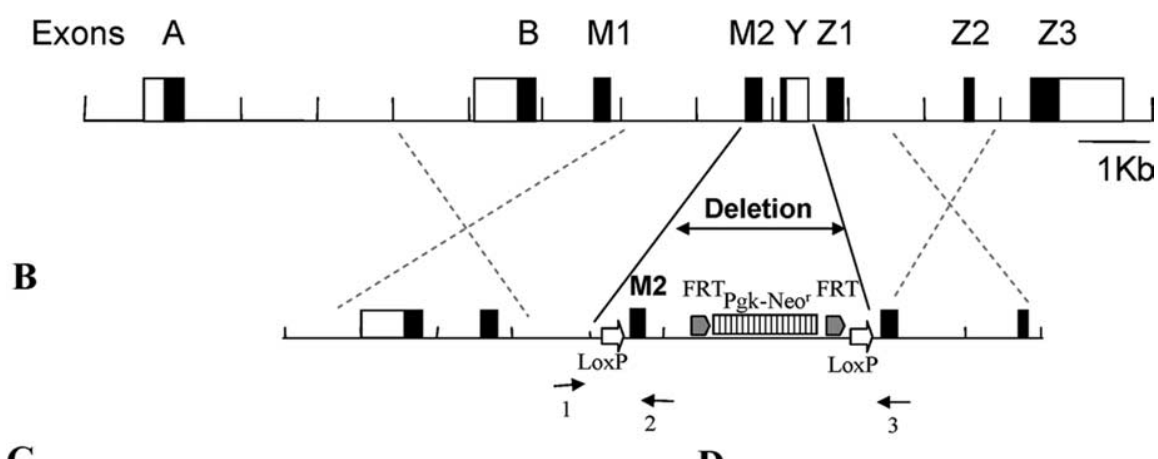

C

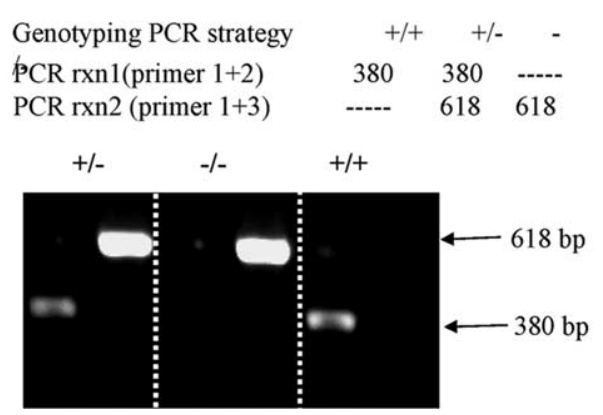

D

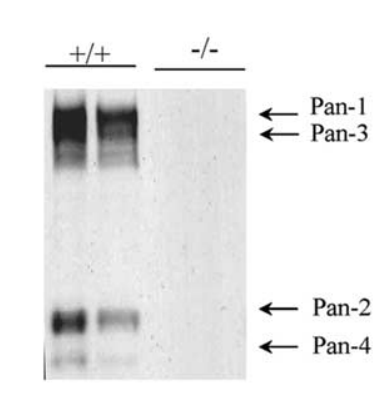

Figure 4. Genetic deletion of pancortins ameliorates ischemic brain damage. $A, B$, Structure of the mouse pancortin gene with box representing exons ( $A, B, M 1, M 2, Y, Z 1, Z 2, Z 3)$ and targeting vector that aimed to delete exon $M 2$ (common to all isoforms) and exon Y. FRT, FLP recognition target; Pgk-Neo, phosphoglycerate kinase I promoter, driving the neomycin phospho-transferase gene. C, Representative PCR products for genotyping using two sets of primers $(1+2$ and $1+3)$. $\boldsymbol{D}$, Immunoblot for pancortins in adult cerebral cortex lysates of WT and pancortin ${ }^{-1-}$ mice.

embryonic mouse brains (Fig. 1A,B). Levels of WAVE1 increased markedly during the first 2 postnatal weeks and remained at high levels in the adult. Pancortins 1 and 3 were present at very low levels in the embryonic mouse brain, increased moderately in the first 2 postnatal weeks, and were present at very high levels in the adult (Fig. $1 B$ ). In contrast, pancortins 2 and 4 were not detected until postnatal day 15 and were present at very high levels in the adult. Immunostaining of adult mouse brains using the monoclonal antibodies raised against pancortins indicated that the majority of cortical neurons express pancortins (Fig. 1C).

During exploration of the function of pancortins, we found that when WAVE1 and pancortin-2 were overexpressed in cultured HEK293 cells, there was a highly significant increase in the number of apoptotic cells at 24 and $48 \mathrm{~h}$ after transfection (Fig. $2 A-C)$. In contrast, overexpression of either WAVE1 or pancortin-2 alone had no significant apoptotic effect. A similar phenomenon was observed when pancortin-2 and WAVE1 were overexpressed in primary cultured cortical and hippocampal neurons established from embryonic day 15 mouse cerebral cortex, a stage of development at which pancortin-2 is not normally expressed (Fig. $1 B$, supplemental Fig. $1 A$, available at www. jneurosci.org as supplemental material; data for survival not shown). These results suggested that WAVE1 and pancortin-2 interact functionally to induce apoptosis. To explore the functions of pancortin-2 and WAVE1 in neuronal apoptosis in the adult brain in vivo, we used a rat model of focal ischemic brain injury in which cortical neurons in the ischemic penumbra undergo apoptosis (Liu et al., 2002). Immunoblot analyses showed that levels of WAVE1, pancortin-2, and Bcl-xL were essentially unchanged in the ischemic cortex at 3,6 , and $24 \mathrm{~h}$ compared with levels in the contralateral cortex of the same rat and in the cortex of sham rats (Fig. 3A). Levels of heat-shock protein 70 were increased in response to ischemia (Fig. 3A), consistent with previous findings (Nowak and Jacewicz, 1994). We next performed immunoprecipitations using a WAVE1 antibody on cortical tissue lysates from the ischemic and contralateral hemispheres from rats that had been subjected to MCAO for 3, 6, and $24 \mathrm{~h}$. Proteins associated with WAVE1 were analyzed by immunoblotting using antibodies against pancortin and Bcl-xL. The results showed that WAVE1, pancortin-2, and Bcl-xL coimmunoprecipitate and that, in cortical tissue from sham-operated control mice, there is a very low level of this threeprotein complex (Fig. 3B). As early as $6 \mathrm{~h}$ after the onset of ischemia, the binding between WAVE1, pancortin-2, and Bcl-xL was markedly increased and remained elevated at $18 \mathrm{~h}$. Interestingly, whereas the increased binding of WAVE1 to Bcl-xL was limited to the ischemic cortex, increased binding of WAVE1 to pancortin-2 occurred in the contralateral cortex as well (Fig. 3B). The protein complex formation reached a peak at $\sim 24 \mathrm{~h}$ after ischemia onset, and by $72 \mathrm{~h}$, the level of pancortin-2 binding to WAVE returned to the basal level (data not shown). Together, these data suggested that focal ischemic stroke caused the enhancement of the interactions between WAVE1, pancortin-2, and Bcl-xL, which was not attributable to a change in the amounts of these proteins in the cells.

\section{Genetic deletion of pancortins protects neurons against ischemic death}

To understand the functions of pancortin-2, its interactions with WAVE1 and Bcl-xL in vivo, and its role in ischemic stroke, we used gene-targeting methods to generate pancortin-deficient mice. Pancortin genes are organized into 8 exons, with transcriptional initiation sites that incorporate either exon $\mathrm{A}$ or exon $\mathrm{B}$ (Fig. 4A). Additional splicing of downstream exons $\mathrm{Y}$ and $\mathrm{Z}$ gives rise to four protein isoforms (pancortins 1-4). We designed a targeting vector to delete exon M2 (common to all isoforms) and exon Y (Fig. 4B). The neo-selection cassette was substituted in place of exon $\mathrm{Y}$ in the target construct, whereas exon M2 was flanked by the loxP sequence to provide flexibility should constitutive pancortin deletion result in embryonic lethality. Mating of F1 generation to Protamine-Cre transgenic mice yielded pancortin null mice that lacked exons $\mathrm{M} 2$ and $\mathrm{Y}$ and were devoid of all pancortin transcripts. Two complementary PCRs were performed to detect the presence of the wild-type allele (618bp) and the targeted null allele (380bp) (Fig. 4C). Immunoblot analysis on protein samples from the cerebral cortex of adult wild-type and pancortin ${ }^{-I-}$ mice confirmed the complete absence of all four pancortin protein isoforms in the pancortin ${ }^{-1-}$ mice (Fig. 4D).

Pancortin ${ }^{-1-}$ mice have a normal lifespan. The only observed abnormality is that homozygous knock-out pairs do not breed well, so we maintain our colony by breeding $-/-$ males with 
A
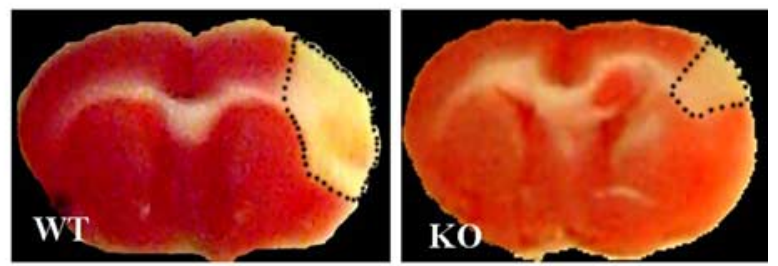

B
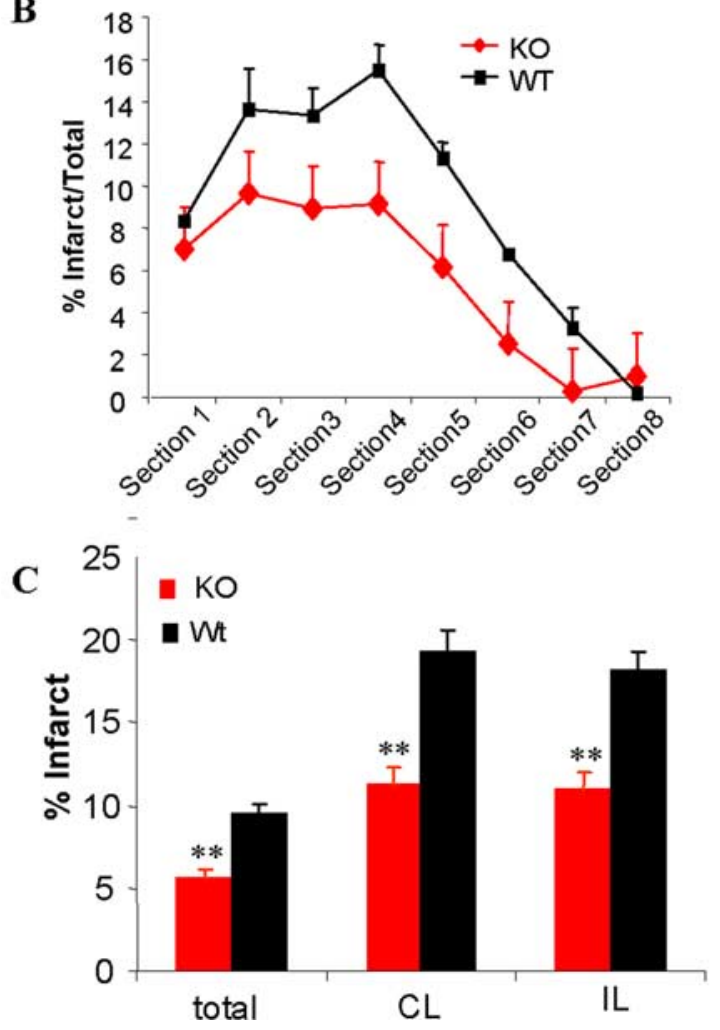

Figure 5. Cerebral infarct size is significantly reduced in pancortin ${ }^{-1-}$ mice compared with WT mice. Pancortin ${ }^{-1-}$ and WT were subjected to middle cerebral artery occlusion for $24 \mathrm{~h} . \boldsymbol{A}$, Representative TTC-stained brain sections (section 4) from WT and pancortin ${ }^{-1-}$ mice. The infarct areas are circled by dotted lines. B, Quantification of infarct size at different rostro-caudal levels. $\boldsymbol{C}$, Infarct volumes in WT and pancortin ${ }^{-1-}$ mice expressed as percentages of total cortical volume, contralateral (CL) volume, or ipsilateral (IL) volume. ${ }^{* *} p<0.01 ; n=20$ WT and 20 pancortin $^{-1-}$ mice. Error bars represent SEM.

$+/-$ females. Based on our finding that co-overexpression of WAVE1 and pancortin-2 induced apoptosis in non-neuronal cell line and primary cultured embryonic neurons, we determined whether pancortin-2 deficiency would result in neuroprotection and reduction of infarct volume after stroke. Adult male wildtype and pancortin ${ }^{-1-}$ mice were subjected to MCAO, and the amount of brain damage that occurred in the ensuing $24 \mathrm{~h}$ was quantified. The cortical infarct size in pancortin ${ }^{-1-}$ mice was significantly less than that in wild-type mice, suggesting a major contribution of pancortin-2 to ischemic neuronal death in vivo (Fig. $5 A-C$ ). Pancortin-2 is not detectable until postnatal day 15 (Fig. $1 B$ ) and, accordingly, pancortin-2 and the other isoforms are not expressed in primary cultured cortical and hippocampal neurons ( $5 \mathrm{~d}$ in culture) established from embryonic day 15 cortex or hippocampus of wild-type mice (supplemental Fig. $1 \mathrm{~A}$, available at www.jneurosci.org as supplemental material). Therefore, the vulnerability to apoptosis of cultured cortical or hippocampal neurons established from embryonic pancortin ${ }^{-1-}$ mice would not be expected to differ from that of neurons from wild-type mice. Indeed, we found that the neuronal death rate induced by growth factor withdrawal was the same in primary cultured cortical neurons established from E15 wild-type and pancortin $^{-1-}$ littermates (supplemental Fig. $1 B, C$, available at www.jneurosci.org as supplemental material).

We next determined whether the interaction of WAVE1, pancortin-2 and Bcl-xL is involved in ischemic neuronal death in the mouse stroke model. Immunoblot analysis showed that levels of WAVE1 and Bcl-xL were unchanged in the cerebral cortex of pancortin-deficient mice compared with wild-type mice (Fig. $6 \mathrm{~A}$, supplemental Fig. 2, available at www.jneurosci.org as supplemental material). However, immunoprecipitation analysis revealed that the amount of Bcl-xL bound to WAVE1 is dramatically decreased in cerebral cortical tissue of pancortin ${ }^{-1-}$ mice compared with wild-type mice at 8 and $24 \mathrm{~h}$ after the onset of the ischemic insult (Fig. $6 B-D$ ). Collectively, the findings to this point indicated that binding of $\mathrm{Bcl}-\mathrm{xL}$ to WAVE1 is dependent on pancortin-2, and pancortin-2 serves a proapoptotic role in focal ischemic stroke by a mechanism related to its binding to WAVE1 and Bcl-xL.

The pancortin-2/WAVE1/Bcl-xL protein complex is associated with mitochondria, and Bax translocation to mitochondria and cytochrome $c$ release is suppressed after brain ischemia in pancortin ${ }^{-/}$mice

WAVE1 proteins coordinate different signaling complexes associated with the actin cytoskeleton in both a tissue-specific and subcellular compartment-specific manner (Machesky et al., 1999; Danial et al., 2003). Considering that Bcl-xL is localized at the mitochondrial membrane (Tsujimoto, 1998), we hypothesized that the WAVE1/pancortin-2/Bcl-xL complex that formed in response to focal ischemic stroke might associate with mitochondria. To test this, we performed cell fractionation experiments on cortical lysates taken from mice $24 \mathrm{~h}$ after the onset of ischemia. The cytosolic, crude mitochondrial, and microsomal extracts were separated by sequential centrifugation. Percoll centrifugation was used to further purify brain mitochondria from other cellular membranes. The purity of the mitochondrial and microsomal fractions was confirmed by showing that the mitochondrial protein Cox-1 was present only in the mitochondrial fraction (Fig. $7 A$ ) and that the endoplasmic reticulum marker Grp-78 was highly enriched in the microsomal fraction (Fig. 7A). WAVE1, pancortin-2, and Bcl-xL were all present in higher amounts in the mitochondrial fraction compared with the other two fractions (Fig. 7A). We next determined whether the WAVE1/pancortin-2/Bcl-xL complex that formed in cortical neurons after focal ischemic injury was associated with mitochondria. Immunoblot analysis indicated no discernable differences in the amounts of WAVE1 and Bcl-xL in the mitochondrial fraction isolated from ischemic and contralateral cortical tissue from wild-type or pancortin-2 $2^{-1-}$ mice (Fig. 7B). In contrast, we found that, in response to brain ischemia, the amount of Bax associated with mitochondria increases in cerebral cortical samples from both wild-type and pancortin ${ }^{-1-}$ mice. However, compared with wild-type mice, the amount of Bax associated with mitochondria is significantly reduced in pancortin ${ }^{-1-}$ mice (Fig. 7C,D).

When the WAVE1 antibody was used to immunoprecipitate proteins in mitochondrial fractions isolated from ischemic cortical tissue ( $24 \mathrm{~h}$ after stroke) of wild-type and pancortin ${ }^{-1-}$ mice, it pulled down both pancortin-2 and Bcl-xL in the mitochondrial fraction of wild-type mice but not in the mitochondrial fraction 
A

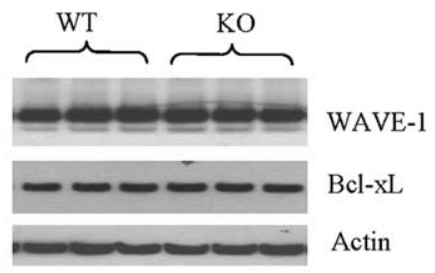

C

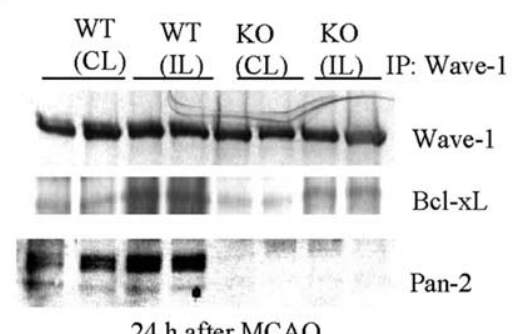

of pancortin $^{-1-}$ mice (Fig. 7E). These findings demonstrated a critical role for pancortin-2 in the formation of a mitochondriaassociated protein complex that includes WAVE1 and Bcl-xL and suggested a role for this protein complex in mitochondrial events in apoptosis.

The process of mitochondrial membrane permeabilization is controlled by the Bcl family members, promoted by the multidomain proteins Bax and Bak, and antagonized by anti-apoptotic members such as Bcl-2 and Bcl-xL (Chao and Korsmeyer, 1998). Consistent with the above data that significantly more Bax is translocated to mitochondria in WT ischemic cortex than in pancortin $^{-1-}$ (Fig. 7C,D), immunoprecipitation analysis revealed that more Bax is pulled down from equal amounts of mitochondria fraction protein from WT ipsilateral cortex compared with sham and pancortin ${ }^{-1-}$ mice (Fig. $7 F$ ). Moreover, the amount of $\mathrm{Bax}$ bound to $\mathrm{Bcl}-\mathrm{xL}$ is dramatically decreased in ischemic cortex of WT mice compared with pancortin ${ }^{-1-}$ mice. These data demonstrate that in pancortin ${ }^{-l-}$ mice, less Bax is associated with the mitochondria and a greater amount of that Bax is associated with, and potentially neutralized by, Bcl-xL. Therefore, interactions of pancortin-2 with WAVE1 and Bcl-xL might sequester the antiapoptotic function of Bcl-xL, resulting in more unbound Bax, which can promote mitochondrial membrane permeabilization.

To support the above hypothesis, we measured the release of cytochrome $c$ from mitochondria, which is a major pathway leading to caspase activation during apoptosis. Indeed, we found that, in response to brain ischemia, large amounts of cytochrome $c$ was present in the cytosolic fraction from the ischemic cortex compared with the contralateral cortex in WT mice (Fig. $8 A, B$ ). The amount of cytochrome $c$ in the cytosolic fraction from the ischemic cortex of pancortin $^{-1-}$ mice was significantly less than that in wild-type mice. We also measured relative amounts of cytochrome $c$ in the mitochondrial fraction of ischemic and control cortical tissue from wild-type and pancortin ${ }^{-1-}$ mice. There is no difference in cytochrome $c$ levels in the sham mitochondria from WT and pancortin $^{-1-}$ mice. After ischemia, however, there is significantly more cytochrome $c$ reserve in the mitochondria of pancortin $^{-1-}$ mice. This supports a major role for pancortin-2 in the postischemic cascade that results in mitochondrial membrane permeabilization and cytochrome $c$ release.

\section{Discussion}

Our findings demonstrate a pivotal role for pancortin-2 in the formation of an apoptosis-associated complex with WAVE1 and Bcl-xL and the death of cortical neurons that occurs after a focal ischemic stroke in mice. Under normal conditions, pancortin-2 is enriched in the adult cerebral cortex but does not interact with WAVE1 and Bcl-xL. In response to ischemic injury, pancortin-2 interacts with both WAVE1 and Bcl-xL. The formation of the pancortin-2/WAVE1/Bcl-xL complex, which appears to be associated with mitochondria, plays a pivotal role in brain damage after a stroke because the complex does not form, and neurons are resistant to ischemic death in pancortin-deficient mice.

Mitochondria play a crucial role in regulating cell death, which is mediated by outer membrane permeabilization in response to death triggers such as DNA damage and growth factor deprivation. Proapoptotic members of Bcl-2 family such as Bax, when activated, translocate to mitochondria to form oligomers that permeabilize the outer membrane of the mitochondria and release proapoptotic factors (e.g., cytochrome $c$ ), leading to caspase activation and cell death. Bcl-xL is believed to prevent apoptosis by blocking the interaction of Bax with the mitochondrial membrane (Chao and Korsmeyer, 1998; He et al., 2003) and/or by preventing Bax from forming oligomers (Yin et al., 1994; Sedlak et al., 1995; Mikhailov et al., 2001). We found that the ischemic cerebral cortex of mice lacking pancortin-2 contains much less Bax associated with mitochondria and a greater percentage of that Bax is bound to Bcl-xL compared with wild-type control mice. Recent studies (Kim et al., 2006) showed that the activity of antiapopotic Bcl-2 family members, such as Bcl-xL, is mediated by sequestering $\mathrm{BH} 3$-only proteins (such as Bim, tBid, and PUMA). Therefore, the possibility also exists that Bcl-xL might lose its function in sequestering $\mathrm{BH} 3$-only proteins as a result of its being sequestered in the WAVE1/pancortin-2 complex. The unsequestered $\mathrm{BH} 3$ proteins can directly activate proapoptotic BAX and BAK, the essential downstream effectors con- 
trolling the mitochondria-dependent cell death program. Indeed, pancortin-2 deficiency results in less ischemia-induced release of cytochrome $c$ from mitochondria. Therefore, pancortin-2 may promote neuronal apoptosis by sequestering $\mathrm{Bcl}-\mathrm{xL}$ in association with WAVE1 and thereby facilitating Bax translocation to the mitochondrial membrane as well as its activation causing mitochondrial membrane permeability transition.

WAVE1 regulates the actin cytoskeleton dynamics by coupling Rho GTPases to the mobilization of the Arp $2 / 3$ complex (Wong and Scott, 2004) and by its A-kinase-anchoring protein (AKAP) properties, which mediate its scaffolding, anchoring, and adaptor protein functions (Carnegie and Scott, 2003). AKAPs play important roles in controlling the flow of signals emanating from transmembrane receptors to downstream targets including mitochondria and the endoplasmic reticulum (Huang et al., 1999; Alto et al., 2002). It was previously reported that WAVE1 is part of a mitochondriaassociated complex that contains PKA, the type-1 protein phosphatase PP1, the proapoptotic protein $\mathrm{BAD}$, and the metabolic enzyme glucokinase in liver cells (Danial et al., 2003). Phosphorylation of BAD by WAVE1-anchored PKA is necessary for glucokinase activity, integrating pathways of glucose metabolism and cell survival and death decisions. In the present study, we identified a mitochondria-associated complex containing WAVE1, pancortin-2, and Bcl-xL that forms in response to ischemic brain injury. WAVE1 was previously reported to be associated with actin cytoskeleton under normal conditions (Machesky et al., 1999; Banzai et al., 2000; Zalevsky et al., 2001). This suggests that ischemia may induce relatively subtle changes in an actin-based protein scaffold that permit interactions between WAVE1, pancortin-2, and Bcl-xL in association with mitochondria and/or lead to WAVE1 translocation to mitochondria. Interestingly, whereas the binding between WAVE1 and Bcl-xL (and release of cytochrome $c$ ) were limited to the ischemic cortex, there was increased binding of WAVE1 to pancortin-2 in both hemispheres compared with sham control mice. This result suggests the possibility that even relatively minor cellular stress that does not result in neuronal death can induce interactions of WAVE1 with pancortin-2. However, the binding of WAVE1 and pancortin-2, although essential, is not sufficient to allow binding (sequestration) of Bcl-xL. Rather, an additional injury cue, present only in the ipsilateral cortex, is required to allow $\mathrm{Bcl}-\mathrm{xL}$ binding to WAVE1 and pancortin-2. Binding of Bcl-xL to WAVE1 is critical for Bax association with mitochondria and release of cytochrome $c$.
B

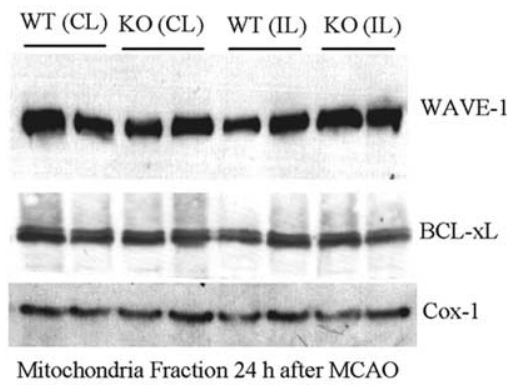

D

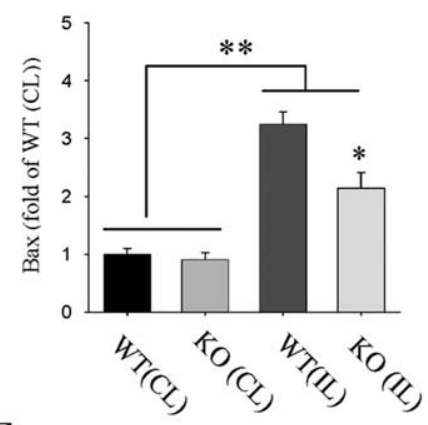

$\mathbf{F}$

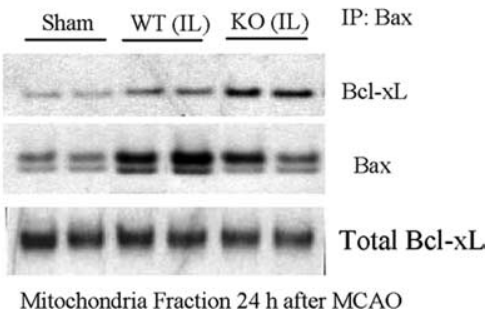

Figure 7. The WAVE1/pancortin-2/BCl-xL protein complex is associated with mitochondria. $A$, Immunoblot for Cox-1, Grp78, WAVE1, pancortin-2, BCl-xL, and actin in cytosolic, mitochondrial, and microsomal cell fractions isolated from mouse cortical tissue by differential centrifugation. $B$, Immunoblot for WAVE1, BCl-xL, and Cox-1 in mitochondrial fractions isolated from contralateral and ipsilateral cerebral cortical tissues from WT and pancortin ${ }^{-1-}$ mice after $24 \mathrm{~h}$ of MCA0. C, Bax association with the mitochondria is suppressed after brain ischemia in pancortin ${ }^{-1-}$ mice. A representative immunoblot of $\mathrm{Bax}$ in the mitochondrial fraction from both contralateral and ipsilateral cerebral cortex of WT and pancortin ${ }^{-1-}$ mice is shown. Blots were re-probed with Cox-1 antibody to control for protein loading. $\boldsymbol{D}$, Results of densitometric analysis of blots of samples from six different mice. Values are the mean and SEM $(n=6) .{ }^{*} p<0.01 . E$, The WAVE1/pancortin-2/BCl-xL protein complex is present in high amounts in the pancortin $^{-1-}$ mice or nonischemic cortex (sham) of WT mice. The lysates of isolated mitochondria from ipsilateral brains were immunoprecipitated with WAVE1 antibodies and subjected to immunoblotting with antibodies to pancortin-2 and BCl-xL. The blots were reprobed with WAVE1 antibodies to control for loading. $F$, A lesser percentage of mitochondria-associated Bax is bound with BCl-xL in ischemic cortex in WT compared with pancortin ${ }^{-1-}$ mice. Lysates of isolated mitochondria were immunoprecipitated with Bax antibody and immunoblotted with antibodies to $\mathrm{BCl}-\mathrm{xL}$ and $\mathrm{Bax}$. Total $\mathrm{BCl}-\mathrm{xL}$ in mitochondria fraction was confirmed by separate Western blot. CL, Contralateral; IL, ipsilateral; IP, immunoprecipitation.

Because pancortin-2 is expressed at high levels in neurons of the adult cerebral cortex but is absent from neurons in the developing cerebral cortex, it may not be involved in programmed cell death during development or in injury- or ischemia-induced damage in the neonatal period. Indeed, we found that embryonic cortical neurons from pancortin-2 null mice and wildtype mice were equally vulnerable to apoptosis triggered by trophic factor withdrawal. It is therefore possible that relative resistance of cortical neurons in neonatal animals to hypoxiaischemia (Towfighi et al., 1997) is attributable, at least in part, to their lack of pancortin-2. Finally, our findings establish 
A

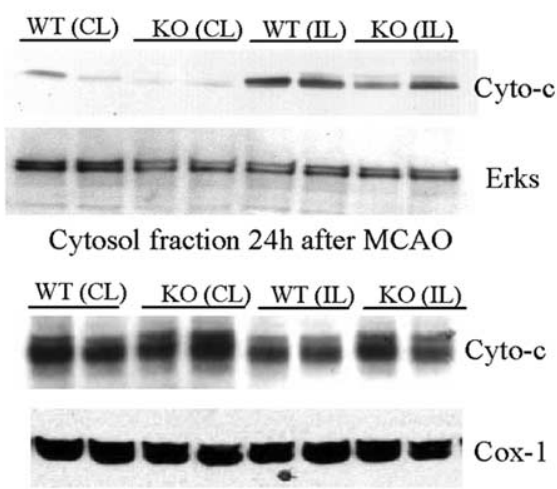

Mitochondria fraction $24 \mathrm{~h}$ after MCAO
B
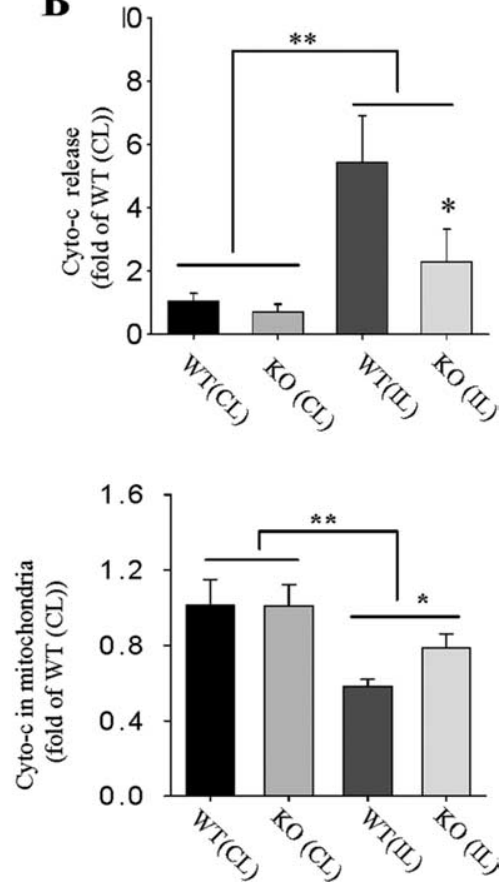

Figure 8. Cytochrome c release is suppressed after brain ischemia in pancortin ${ }^{-1-}$ mice. $A$, Immunoblot analyses of cytochrome c (Cyto-c) in the cytosolic fraction and in the mitochondrial fraction from both contralateral (CL) and ipsilateral (IL) cerebral cortex of WT and pancortin ${ }^{-1-}$ mice. Blots were reprobed with Erks (cytosol) and Cox-1 (mitochondria) antibodies to control for protein loading. $\boldsymbol{B}$, Results of densitometric analysis of blots of samples from six different mice. Values are the mean and SD $(n=$ 6). ${ }^{*} p<0.05$ and ${ }^{* *} p<0.01$.

pancortin-2 as a novel target for therapeutic intervention in stroke. Agents that inhibit the interactions of pancortin-2 with WAVE1 and/or Bcl-xL would be expected to prevent the death of neurons after stroke.

\section{References}

Alto NM, Soderling J, Scott JD (2002) Rab32 is an A-kinase anchoring protein and participates in mitochondrial dynamics. J Cell Biol 158:659-668.

Ando K, Nagano T, Nakamura A, Konno D, Yagi H, Sato M (2005) Expression and characterization of disulfide bond use of oligomerized A2-pancortins: extracellular matrix constituents in the developing brain. Neuroscience 133:947-957.

Banzai Y, Miki H, Yamaguchi H, Takenawa T (2000) Essential role of neural Wiskott-Aldrich syndrome protein in neurite extension in PC12 cells and rat hippocampal primary culture cells. J Biol Chem 275:11987-11992.

Basanez G, Sharpe JC, Galanis J, Brandt TB, Hardwick JM, Zimmerberg J (2002) Bax-type apoptotic proteins porate pure lipid bilayers through a mechanism sensitive to intrinsic monolayer curvature. J Biol Chem 277:49360-49365.

Carnegie GK, Scott JD (2003) A-kinase anchoring proteins and neuronal signaling mechanisms. Genes Dev 17:1557-1568.

Chao DT, Korsmeyer SJ (1998) BCL-2 family: regulators of cell death. Annu Rev Immunol 16:395-419.

Cheng A, Chan SL, Milhavet O, Wang S, Mattson MP (2001) p38 MAP kinase mediates nitric oxide-induced apoptosis of neural progenitor cells. J Biol Chem 276:43320-43327.

Chua BT, Volbracht C, Tan K, Li R, Yu VC, Li P (2003) Mitochondrial translocation of cofilin is an early step in apoptosis induction. Nat Cell Biol 5:1083-1089.

Dahl JP, Wang-Dunlop J, Gonzales C, Goad ME, Mark RJ, Kwak SP (2003) Characterization of the WAVE1 knock-out mouse: implications for CNS development. J Neurosci 23:3343-3352.

Danial NN, Gramm CF, Scorrano L, Zhang CY, Krauss S, Ranger AM, Datta SR, Greenberg ME, Licklider LJ, Lowell BB, Gygi SP, Korsmeyer SJ

(2003) BAD and glucokinase reside in a mitochondrial complex that integrates glycolysis and apoptosis. Nature 424:952-956.

Dirnagl U, Iadecola C, Moskowitz MA (1999) Pathobiology of ischaemic stroke: an integrated view. Trends Neurosci 22:391-397.

Furukawa K, Fu W, Li Y, Witke W, Kwiatkowski DJ, Mattson MP (1997) The actin-severing protein gelsolin modulates calcium channel and NMDA receptor activities and vulnerability to excitotoxicity in hippocampal neurons. J Neurosci 17:8178-8186.

Ghribi O, Herman MM, Forbes MS, De Witt DA, Savory J (2001) GDNF protects against aluminum-induced apoptosis in rabbits by upregulating Bcl-2 and $\mathrm{Bcl}-\mathrm{xL}$ and inhibiting mitochondrial Bax translocation. Neurobiol Dis 8:764-773.

Glazner GW, Mattson MP (2000) Differential effects of BDNF, ADNF9, and TNFalpha on levels of NMDA receptor subunits, calcium homeostasis, and neuronal vulnerability to excitotoxicity. Exp Neurol 161:442-452.

Harms C, Bosel J, Lautenschlager M, Harms U, Braun JS, Hortnagl H, Dirnagl U, Kwiatkowski DJ, Fink K, Endres M (2004) Neuronal gelsolin prevents apoptosis by enhancing actin depolymerization. Mol Cell Neurosci 25:69-82.

He L, Perkins GA, Poblenz AT, Harris JB, Hung M, Ellisman MH, Fox DA (2003) Bcl-xL overexpression blocks bax-mediated mitochondrial contact site formation and apoptosis in rod photoreceptors of lead-exposed mice. Proc Natl Acad Sci USA 100:1022-1027.

Huang LJ, Wang L, Ma Y, Durick K, Perkins G, Deerinck TJ, Ellisman MH, Taylor SS (1999) NH2-terminal targeting motifs direct dual specificity A-kinase-anchoring protein 1 (D-AKAP1) to either mitochondria or endoplasmic reticulum. J Cell Biol 145:951-959.

Kim H, Rafiuddin-Shah M, Tu HC, Jeffers JR, Zambetti GP, Hsieh JJ, Cheng EH (2006) Hierarchical regulation of mitochondrion-dependent apoptosis by BCL-2 subfamilies. Nat Cell Biol 8:1348-1358.

Liu D, Lu C, Wan R, Auyeung WW, Mattson MP (2002) Activation of mitochondrial ATP-dependent potassium channels protects neurons against ischemia-induced death by a mechanism involving suppression of Bax translocation and cytochrome $\mathrm{c}$ release. J Cereb Blood Flow Metab 22:431-443.

Machesky LM, Mullins RD, Higgs HN, Kaiser DA, Blanchoin L, May RC, Hall ME, Pollard TD (1999) Scar, a WASP-related protein, activates nucleation of actin filaments by the Arp $2 / 3$ complex. Proc Natl Acad Sci USA 96:3739-3744.

Marzo I, Brenner C, Zamzami N, Susin SA, Beutner G, Brdiczka D, Remy R, Xie ZH, Reed JC, Kroemer G (1998) The permeability transition pore complex: a target for apoptosis regulation by caspases and bcl-2-related proteins. J Exp Med 187:1261-1271.

Mattson MP, Kroemer G (2003) Mitochondria in cell death: novel targets for neuroprotection and cardioprotection. Trends Mol Med 9:196-205.

Mikhailov V, Mikhailova M, Pulkrabek DJ, Dong Z, Venkatachalam MA, Saikumar P (2001) Bcl-2 prevents Bax oligomerization in the mitochondrial outer membrane. J Biol Chem 276:18361-18374.

Nagano T, Nakamura A, Mori Y, Maeda M, Takami T, Shiosaka S, Takagi H, Sato M (1998) Differentially expressed olfactomedin-related glycoproteins (Pancortins) in the brain. Mol Brain Res 53:13-23.

Nagano T, Nakamura A, Konno D, Kurata M, Yagi H, Sato M (2000) A2Pancortins (Pancortin-3 and -4) are the dominant pancortins during neocortical development. J Neurochem 75:1-8.

Nowak TS, Jacewicz M (1994) The heat shock/stress response in focal cerebral ischemia. Brain Pathol 4:67-76.

Polster BM, Fiskum G (2004) Mitochondrial mechanisms of neural cell apoptosis. J Neurochem 90:1281-1289.

Sedlak TW, Oltvai ZN, Yang E, Wang K, Boise LH, Thompson CB, Korsmeyer 
SJ (1995) Multiple Bcl-2 family members demonstrate selective dimerizations with Bax. Proc Natl Acad Sci USA 92:7834-7838.

Stradal E, Rottner K, Disanza A, Confalonieri S, Innocenti M, Scita G (2004) Regulation of actin dynamics by WASP and WAVE family proteins. Trends Cell Biol 14:303-311.

Takenawa T, Miki H (2001) WASP and WAVE family proteins: key molecules for rapid rearrangement of cortical actin filaments and cell movement. J Cell Sci 114:1801-1809.

Tang HL, Le AH, Lung HL (2006) The increase in mitochondrial association with actin precedes Bax translocation in apoptosis. Biochem J 396:1-5.

Towfighi J, Mauger D, Vannucci RC, Vannucci SJ (1997) Influence of age on the cerebral lesions in an immature rat model of cerebral hypoxiaischemia: a light microscopic study. Dev Brain Res 100:149-160.

Trapp T, Olah L, Holker I, Besselmann M, Tiesler C, Maeda K, Hossmann KA (2001) GTPase RhoB: an early predictor of neuronal death after transient focal ischemia in mice. Mol Cell Neurosci 17:883-894.
Tsujimoto Y (1998) Role of Bcl-2 family proteins in apoptosis: apoptosomes or mitochondria? Genes Cells 3:697-707.

Truelsen T, Bonita R (2003) Advances in ischemic stroke epidemiology. Adv Neurol 92:1-12.

Wong W, Scott JD (2004) AKAP signaling complexes: focal points in space and time. Nat Rev Mol Cell Biol 5:959-970.

Yin XM, Oltvai ZN, Korsmeyer SJ (1994) BH1 and BH2 domains of Bcl-2 are required for inhibition of apoptosis and heterodimerization with Bax. Nature 369:321-323.

Zalevsky J, Lempert L, Kranitz H, Mullins RD (2001) Different WASP family proteins stimulate different Arp2/3 complex-dependent actinnucleating activities. Curr Biol 11:1903-1913.

Zong WX, Lindsten T, Ross AJ, MacGregor GR, Thompson CB (2001) $\mathrm{BH} 3$-only proteins that bind pro-survival Bcl-2 family members fail to induce apoptosis in the absence of Bax and Bak. Genes Dev 15:1481-1486. 